\title{
«Dale un bofetón ella»
}

\section{«She gives him a slap»}

\section{Marcella Trambaioli}

Università del Piemonte Orientale

ITALIA

marcella.trambaioli@uniupo.it

[Hipogrifo, (issn: 2328-1308), 7.1, 2019, pp. 421-437]

Recibido: 03-03-2018 / Aceptado: 20-04-2018

DOI: http://dx.doi.org/10.13035/H.2019.07.01.32

Resumen. En las relaciones entre hombres y mujeres, muy a menudo conflictivas, el significado y las implicaciones de un bofetón cambian radicalmente según quién es la víctima del golpe. Con muy pocas excepciones, los ejemplos espigados (El laberinto de amor de Cervantes; Del mal, lo menos, El primero Benavides, La fuerza lastimosa, El duque de Viseo, Las ferias de Madrid, Los locos de Valencia, Por la puente, Juana y El perro del hortelano de Lope; El condenado por desconfiado, Doña Beatriz de Silva, El amor médico, La celosa de sí misma de Tirso; Las manos blancas no ofenden de Calderón) no hacen sino confirmar que un lance violento, aunque sea el de un mero bofetón, pertenece al mundo masculino, y que puede atañer al comportamiento femenino tan solo en el mundo al revés de la risa carnavalesca, siendo los celos amorosos o el gratuito disparate festivo los pretextos dramáticos para que las manos blancas puedan soltar una bofetada más bien dada.

Palabras clave. Bofetón/bofetada; comedia seria; comedia cómica; celos amorosos; disparate gratuito; Cervantes; Lope; Tirso; Calderón.

Abstract. In the relationships between men and women, quite always based on conflict, the meaning and the implications of a slap change completely depending on the sex of the victim. With a few exceptions, the selected examples of this essay (Cervantes' El laberinto de amor; Lope's Del mal, lo menos, El primero Benavides, La fuerza lastimosa, El duque de Viseo, Las ferias de Madrid, Los locos de Valencia, Por la puente, Juana y El perro del hortelano; Tirso's El condenado por desconfiado, Doña Beatriz de Silva, El amor médico, La celosa de sí misma; Calderón's Las manos blancas no ofenden) confirm that even a violent act such as a slap belongs to the masculine dimension, and that it may concern the feminine behavior just in the Carnival upside down dimension, considering that jealousy and the comic nonsense are the dramatic pretext for justifying a slap given by a woman hand. 
Keywords. Slap; Drama; Comedy; Jealousy; Comic nonsense; Cervantes; Lope; Tirso; Calderón.

«Recibir bofetón es infamia» reza Covarrubias en su Tesoro de la lengua casteIlana; «el bofetón es afrenta terrible» remacha don Juan de Mendoza en la primera secuencia dramática de Del mal, lo menos de Lope de Vega ${ }^{1}$, claro está cuando el golpe se lo da un hombre a otro varón en una intriga seria. El repertorio de comedias de tema histórico-legendario nos depara numerosos casos de bofetones capaces de desencadenar el conflicto dramático. Brindemos un ejemplo al azar. En El primero Benavides aún de Lope, el viejo don Mendo es abofeteado por el soberbio y arrogante Payo de Vivar, quien pretende llevarse a sus tierras a Alfonso $\checkmark$, hijo del difunto rey Bermudo II de León, con el apoyo de otros nobles. El anciano afrentado, antes de marcharse, denuncia la vil actuación de sus contrincantes haciendo resaltar su propia integridad moral:

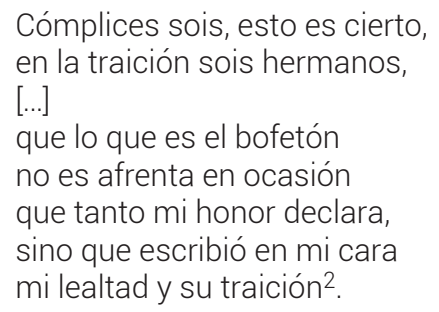

Con el deseo de vengarse, decide recurrir a Sancho, su nieto bastardo, hijo del rey Bermudo y de Clara de Benavides, para desafiar y matar al responsable de su agravio. Con todo, en el clímax él mismo conseguirá asesinar a Payo a traición con una daga. Adviértase que semejante desenlace no es azaroso dado que el término «bofetón» se puede aplicar también al golpe dado con un arma. Dice Galván en el acto intermedio de El condenado por desconfiado de Tirso de Molina, aludiendo al pendenciero Enrico: «Este busca que le den / un bofetón con la daga» ${ }^{3}$. En este sentido el viejo Mendo logra vengarse conforme a la ley tribal del ojo por ojo.

El que propina la bofetada suele ser un personaje soberbio y moralmente censurable $y$, por lo general, es un varón joven que afrenta a un hombre mayor. El protagonista de la pieza tirsiana mencionada encarna el tipo de manera acabada; apuntemos que en el largo parlamento de la jornada I, enumerando sus muchos crímenes y liviandades, Enrico confiesa:

Por hacer mal solamente,

he jurado juramentos

falsos, fingido quimeras,

hecho máquinas y enredos;

1. Lope de Vega, Del mal, lo menos, p. 832, vv. 45-46.

2. Lope de Vega, El primero Benavides, p. 871, vv. 61-70.

3. Tirso de Molina, El condenado por desconfiado, p. 125, vv. 1305-1306. 
y un sacerdote que quiso

reprenderme con buen celo,

de un bofetón que le di,

cayó en tierra medio muerto ${ }^{4}$

En La moza de cántaro, comedia del Lope casi de senectute, don Bernardo recibe una bofetada de un soberbio don Diego, quien aspira a la mano de su hija, doña María, a raíz de una carta en que el duque de Medinaceli, deudo del viejo caballero, cuestiona su nobleza. A duras penas don Bernardo accede a confesar a su hija la afrenta recibida:

Herrado traigo, María,

el rostro con cinco letras.

Esclavo soy de la infamia,

cautivo soy de la afrenta ${ }^{5}$.

El que debería desagraviar al viejo es el hijo varón, don Alonso, quien se encuentra en Flandes, por lo que doña María, ducha en el uso de las armas, determina ir a matar a don Diego, que por su acción deshonrosa ha sido encarcelado. Tras entrar en su celda, la dama finge aceptar el casamiento para hacer las paces, pero, cuando va a abrazarle, según reza la acotación: «saca una daga, y dale con ella», echándole en cara su infamia:

¿En canas tan venerables

pusiste la mano, perro?

Pues estas hazañas hacen

las mujeres varoniles ${ }^{6}$.

El bofetón de don Diego, pues, no solo desencadena la reacción de una mujer capaz de cometer un delito para lavar la honra familiar? sino que, al igual que en El primero Benavides, provoca la muerte de quien lo ha propinado.

En muy otra vertiente, según las enseñanzas del cristianismo, el bofetón se relaciona con la idea de perdón, y en esta acepción se incrusta en una réplica de Enrique, en el acto intermedio de La fuerza lastimosa de Lope, antes de que el Conde se percate de que el despiadado rey de Irlanda lo está sometiendo a una prueba que implicará, muy a su pesar, la muerte de su esposa Isabela:

También le manda Dios al que recibe un bofetón, que ponga el otro lado y en el mundo es deshonra, y es la honra vengarse, siendo siempre la venganza odiosa a Dios, cuanto apacible al hombre ${ }^{8}$.

4. Tirso de Molina, El condenado por desconfiado, p. 99, vv. 828-835.

5. Lope de Vega, La moza de cántaro, p. 1002.

6. Lope de Vega, La moza de cántaro, p. 1004.

7. Cfr. Trambaioli, en prensa.

8. Lope de Vega, La fuerza lastimosa, p. 152, vv. 1614-1618. 
A la luz de lo que va a ocurrir a continuación, las palabras del galán protagonista funcionan como un trágico contrapunto de las circunstancias en que se va a encontrar.

En las relaciones entre hombres y mujeres, muy a menudo conflictivas, el significado y las implicaciones de un bofetón cambian radicalmente según quién es la víctima del golpe. Si se trata de una mujer, entramos en el ámbito cultural de la supeditación femenina al varón (hoy hablaríamos sin rodeos de violencia de género), y desde el punto de vista teatral quedamos en el macrogénero de la comedia seria. El gesto afrentoso no se tiene necesariamente que producir en una relación de pareja; basta con que una mujer se atreva a plantarle cara a un hombre para suscitar su violenta reacción. Es lo que le ocurre, por ejemplo, a doña Inés quien contesta con insolencia al duque de Guimarães, hermano del Condestable, en el acto de apertura de la pieza lopesca El duque de Viseo:

$\begin{array}{ll}\text { GUIMARÁNS } & \begin{array}{l}\text { ¡Ya para tanto desprecio } \\ \text { la paciencia me faltó! }\end{array} \\ & \text { Dale un bofetón } \\ & \begin{array}{l}\text { Aprended con esto a hablar } \\ \text { y a guardar secreto. }\end{array} \\ \text { DOÑA INÉS } & \begin{array}{l}\text { ¡Ah, cielos! } \\ \text { ¡A mí bofetón! }\end{array} \\ \text { GUIMARÁNS } & \text { Son celos }\end{array}$

Tras lo cual, según informa la indicación escénica: «A las voces que dio doña Inés por el bofetón, sale el Rey, [don Egas] y el duque de Viseo, el Condestable, el conde de Faro y don Álvaro de Portugal [...] $»^{10}$. La dama ultrajada, antes de retirarse del escenario, no deja de denunciar con fuerza al soberano las traiciones de su ofensor. De todas formas, siendo una mujer, no puede ser ella la que se vengue de Guimarães, tal como se apresura a subrayar don Egas, dirigiéndose al Rey:

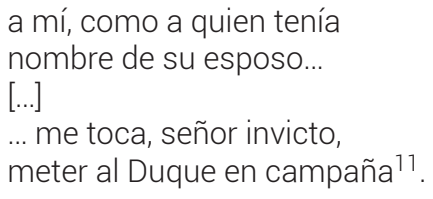

En definitiva, conforme a las rígidas normas socio-culturales de la época, es como si la bofetada la hubiera recibido el hombre depositario y responsable de la honra de la dama.

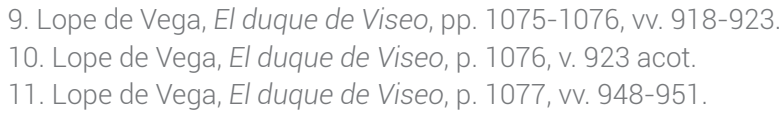


Es muy raro que un varón reciba un bofetón por parte de una mujer en una comedia seria, pero es lo que ocurre en Doña Beatriz de Silva, obra hagiográfica de Tirso. No parece azaroso que el golpe se produzca entre unos personajes secundarios. Don Juan, hermano de Beatriz, la primera dama y futura santa, ama desde sus tiernos años a la infanta doña Leonor, destinada a casarse con el emperador Federico. Cuando los dos vuelven a encontrarse en Roma en el acto II, la que ya es emperatriz, consciente de sus deberes conyugales y políticos, rechaza definitivamente al antiguo pretendiente. La acotación apunta el momento de extremada tensión en que Leonor tropieza: «al darla la mano, don Juan se la aprieta y quiere besársela y ella le da un bofetón» ${ }^{12}$. La mujer, tajante, le advierte:

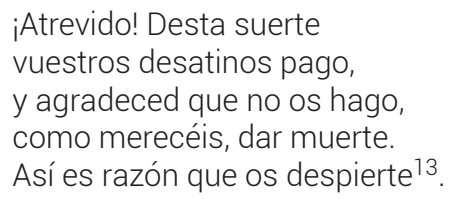

Don Juan, humillado, comprenderá que ya es hora de renunciar a los «profanos gustos» ${ }^{14}$ para tomar la senda religiosa, de forma análoga a lo que hará su hermana en la acción principal de la obra. La jocosa intervención del gracioso Melgar, que juega con la bisemia de las palabras «cardenal» $\mathrm{y}$ «Roma» para comentar las secuelas del golpe que don Juan ha recibido en plena cara ${ }^{15}$, destaca con tono malicioso que en el plano del decoro su amo ha padecido un acto injurioso: «Afrenta debe de ser / dejarse un hombre poner / salserillas de color» ${ }^{16}$. No obstante, el horizonte religioso de la pieza convierte el bofetón en una oportunidad de salvación para el personaje masculino que lo ha recibido.

Como es de esperar, donde no faltan los varones que resultan abofeteados por una mujer es en el mundo al revés de la comedia cómica y del teatro breve. Al fin y al cabo, las manos blancas no ofenden, tal como dictamina una frase proverbial que Calderón emplea como título de una lograda comedia de enredo, sobre la cual nos detendremos más adelante. Dicho de otra manera, un acto violento que entre hombres y en un contexto grave asume el significado de una afrenta deshonrosa, cuando es cometido por una mujer en el teatro cómico se enmarca en el ámbito del cortejo y de los celos amorosos, o bien en una dimensión plenamente carnavalesca ${ }^{17}$. En el primero de los dos casos, cabe preguntarse con Aurelio González:

12. Tirso de Molina, Doña Beatriz de Silva, p. 943, v. 1968 acot.

13. Tirso de Molina, Doña Beatriz de Silva, p. 943, vv. 1977-1981.

14. Tirso de Molina, Doña Beatriz de Silva, p. 945, v. 2043.

15. Tirso de Molina, Doña Beatriz de Silva, p. 944, vv. 1987-2000: «Sin mentís un bofetón / es como rayo sin trueno; / tu carrillo queda bueno / para rueda de salmón. / Quiere que, en esta ocasión, / tu amor a Roma te iguales, / que, en prueba desas señales, / fuera, porque te autorices, / tu cara, a estar sin narices, / Roma con sus cardenales. / Cinco en la cara te ha puesto; / si fue favor, no me espanto, / mas favor que duele tanto / más es quinto que no sexto».

16. Tirso de Molina, Doña Beatriz de Silva, p. 946, vv. 2048-2050.

17. En este sentido el bofetón entraría en la categoría de los lances violentos presentes en las comedias de capa y espada y en las piezas palatinas que, según Castro Rivas, son «sucesos sin trascendencia 
«¿cuál es el peso del gesto en la expresión amorosa?, ¿sublima o vuelve directa la expresión?» ${ }^{18}$. Para contestar acudamos a unos ejemplos concretos.

Las ferias de Madrid, comedia primeriza de Lope de Vega, nos proporciona el caso de una dama que tan solo amenaza con golpear a un varón con su abanico para defenderse de su cortejo apremiante y desfachado. Durante la feria de San Mateo en la Villa y Corte, en un ambiente chispeante y desenfadado, un grupo de galanes aprovecha el barullo para buscar aventuras amorosas. Leandro empieza a galantear a Violante, disfrazada de labradora, y en el crescendo malicioso de las réplicas se insinúa el motivo que nos interesa:

$\begin{array}{ll}\text { LEANDRO } & \text { ¿Agora viento queréis? } \\ \text { VIOLANTE } & {[\ldots]} \\ & \begin{array}{l}\text { Es para templar, señor, } \\ \text { ese fuego que os abrasa. }\end{array} \\ \text { LEANDRO } & \text { La mano podrá sin él... } \\ \text { VIOLANTE } & \begin{array}{l}\text {... daros algún bofetón, } \\ \text { y será de condición } \\ \\ \end{array} \\ & \text { que os acordéis siempo pesada la mano dél: }\end{array}$

Sin embargo, la amenaza no se convierte en acción porque, de hecho, esta pareja, aun en el ambiente apicarado de la comedia ${ }^{20}$, es la única destinada a vivir un sentimiento amoroso que trasciende el mero erotismo ${ }^{21}$, pese a que ella está casada. De hecho, el marido de la dama, Patricio, la traiciona con Eugenia, y su condición de malmaridada justifica su enamoramiento por Leandro. Por lo demás, el sangriento desenlace de la pieza, en que Belardo, padre de Violante, mata al yerno engañador, permitiendo que la hija se case con el amado Leandro tras respetar el debido año de luto, se debe a las audacias del Lope primerizo, destinadas a esfumarse en la fórmula madura de la Comedia Nueva.

trágica ninguna [...] que muchas veces aportan ingredientes agraviantes e injuriosos, pero siempre al servicio de la comicidad, del humor y de la risa».

18. González, 2003, p. 87

19. Lope de Vega, Las ferias de Madrid, p. 1862, vv. 882-891.

20. Ver Campana, 2001, p. 80.

21. Ver Trambaioli, 2015, pp. 95-96: «Tal como ocurre a menudo en la producción primeriza de Lope, la trama es bastante confusa, aparecen hasta seis galanes y se entrecruzan varios hilos argumentales. No obstante, el que constituye la acción principal es protagonizado por un caballero que se llama Leandro. Según se puede comprobar analizando los acontecimientos, es como si el nombre determinara a priori las acciones del personaje, quien tiene absoluta conciencia del rol que le ha tocado. Diríamos que Lope, al fin de destacar que la relación entre Leandro y Violante es la única historia de amor verdadero en un contexto de inmoralidad generalizada, que no deja de afectar también a la pareja protagonista, siente la urgencia de estructurarla literariamente, sembrando la textura poética de la pieza de referencias a los amores legendarios de Hero y Leandro». 
En realidad, tratándose de un acto impropio para el decoro de una dama - «las damas no desdigan de su nombre» advierte el dramaturgo en el Arte nuevo (v. 280) -, suele ser una criada la que propina la bofetada a su correspondiente masculino en la acción secundaria. Un ejemplo de ello lo hallamos en El amor médico de Tirso. En el acto de clausura, en una secuencia en que la proteica protagonista, Jerónima, aparece tapada en compañía de Quiteria, Tello se dirige a la segunda con ademanes y términos burlescos y, al intentar descubrirla, según reza la acotación, «ella le da un bofetón», provocando la reacción descompuesta del gracioso: «iCarrillo barre! / ¡Ay, quebróme una mejilla!»22. Dicha secuencia farsesca -que, desde luego, resulta paródica con respecto a situaciones análogas (pero sin bofetadas) vividas por los dos protagonistas - se incrusta dignamente en el contexto festivo de esta comedia palatina del mercedario, cuyos ingredientes principales, en palabras de Oteiza, son «comicidad e ingenio» ${ }^{23}$.

Un caso semejante, aún de Tirso, se incrusta en el acto de apertura de La celosa de sí misma: don Melchor y Ventura, que acaban de llegar de León a Madrid donde al caballero le espera el matrimonio con doña Magdalena, hija de un rico perulero, oyen misa en una capilla y el galán queda fulgurado por la belleza de la mano de una feligresa tapada, que resultará ser su prometida:

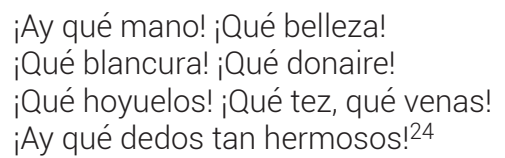

A la exaltación del amo hace eco el gracioso con una visión deformada del mismo detalle corporal, vinculándolo a la naturaleza pedigüeña de las mujeres conforme a la vena satírico-burlesca propia de su papel: «iAy qué uñas aguileñas! / iAy qué bello rapto, rapis!» ${ }^{25}$. Al salir de la capilla, el caballero corteja a la dama, haciendo nuevamente hincapié en su hermosa extremidad: «Sol hermoso, mano mía», y Ventura hace lo propio con Quiñones, la criada de aquella, con una sarta de imágenes y términos grotescos:

¿Tiene vuesa dueñería

la mano, cual su señora,

culta, animada, esplendora,

gaticinante y arpía?

Brillarale la uñería

cuando el caldo escudillice

o la loza estropajice,

exhalando cada vez

22. Tirso, El amor médico, p. 811, vv. 3095-3096.

23. Oteiza, en Tirso, El amor médico, p. 663

24. Tirso, La celosa de sí misma, p. 1445; más adelante, don Melchor remacha: «Una mano hermosa, / blanca, poblada y perfecta, / que tiene acciones por almas / y tiene dedos por lenguas, / hará enamorar un mármol».

25. Tirso, La celosa de símisma, p. 1445. 


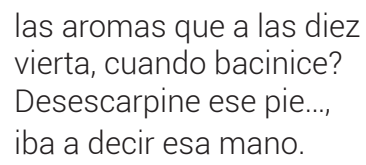

Por la ley del contrapunto cómico, la criada le propina una bofetada — «Jo, majadero» ${ }^{26}$-, pagándole su descompuesto galanteo con la violenta reacción de la extremidad tan ridiculizada. Cabe considerar al respecto que todas las equivocaciones con que se construye el enredo dramático estriban en la hermosa mano de la protagonista que - no se nos escape- es símbolo de la unión amorosa, como bien sabe el don Juan del Burlador. De manera que el bofetón de Quiñones asume una función emblemática central en la dimensión paródica de la pieza.

En Por la puente, Juana, comedia del Lope de senectute, una criada amenaza con dar al gracioso un bofetón por culpa de la primera dama disfrazada de labradora. Isabel/Juana, obligada a servir en casa de Antonia a la espera de hallar noticias de su amado don Juan, hechiza con su belleza a todos los hombres que dan con ella, incluso a Esteban, el criado del Marqués quien, de buenas a primeras, estaba interesado en Inés. En el cierre del acto de apertura, el gracioso manifiesta su jocosa admiración confesando que la hermosura de la fingida fregona lo ha dejado aturdido: "Juana me ha muerto, señores; / reñí con ella sin armas. / ¡Qué virotazo me ha dado!» ${ }^{27}$. En el acto III, las dos mujeres aparecen en la Vega, lugar de recreo, como dos damas tapadas en búsqueda de don Juan, pero muy a deshora padecen el acoso del Marqués y Esteban. Ante la negativa de la protagonista de descubrirse, el criado se le dirige con tono desenvuelto: «Oye, señora tapada, / menos desdenes». Tras lo cual, el diálogo, como tiene que ser, se desarrolla entre los dos graciosos:

\begin{tabular}{ll}
\multicolumn{1}{c}{ Ataje } \\
INÉS & $\begin{array}{l}\text { la manopla, señor paje, } \\
\text { o habrá coz y bofetada. }\end{array}$ \\
ESTEBAN & $\begin{array}{l}\text { Eres haca, que no creo } \\
\text { que eres mujer; pero advierte } \\
\text { que soy paje de alta suerte, } \\
\text { y que en señoras me empleo }\end{array}$
\end{tabular}

Trámite la ironía dramática el público sabe que el bofetón amenazado por la criada - que a lo largo de la acción se muestra justamente ofendida por los desdenes del gracioso y que, al final, no se casará con él, quedando los dos sueltos ${ }^{29}-$

26. Tirso, La celosa de sí misma, p. 1448.

27. Lope de Vega, Por la puente, Juana, p. 1288.

28. Lope de Vega, Por la puente, Juana, p. 1299.

29. Ver Trambaioli, 2015, p. 384: «en el desenlace se unen en matrimonio solo los dos caracteres principales, Juana-Isabel de Nevares y don Diego-don Juan del Valle, quedando sueltos todos los demás personajes [...] Tampoco los criados Esteban e Inés se casan, tras protagonizar una turbulenta relación sentimental a causa de los celos que, a lo largo de la acción, la segunda experimenta por culpa de la 
suena como un digno contrapunto paródico del virotazo figurado de la secuencia recortada del acto inicial.

Según me consta, la dama de comedia que desdice de su nombre dando el bofetón más bien dado es la Diana de El perro del hortelano, joya dramática de la madurez de Lope de Vega, que Pilar Miró supo transponer en película con maestría inigualable. Casi al final del acto intermedio, cuando la tensión dramática y erótica alcanza su punto álgido, y Teodoro, exasperado, ya no sabe a qué santo encomendarse y trae a colación el refrán capaz de sintetizar sutilmente el comportamiento de la Condesa, esta le echa en cara que Marcela no puede ser suya. El secretario, no obstante, intenta afirmar su derecho de amar y ser amado, suscitando las iras incontenibles de la enamorada Diana:

\begin{tabular}{|c|c|}
\hline TEODORO & $\begin{array}{l}\text { ¿No hay remedio? } \\
\text { Pues, ¿quiere vuseñoría } \\
\text { que, si me quiere y la quiero, } \\
\text { ande a probar voluntades? } \\
\text { ¿Tengo yo de tener puesto, } \\
\text { adonde no tengo gusto, } \\
\text { mi gusto por el ajeno? } \\
\text { Yo adoro a Marcela y ella } \\
\text { me adora, y es muy honesto } \\
\text { este amor. }\end{array}$ \\
\hline DIANA & $\begin{array}{c}\text { ¡Pícaro infame! } \\
\text { Haré yo que os maten luego }\end{array}$ \\
\hline TEODORO & ¿Qué hace vuseñoría? \\
\hline DIANA & $\begin{array}{l}\text { Daros, por sucio y grosero, } \\
\text { estos bofetones } 30\end{array}$ \\
\hline
\end{tabular}

Está claro que el bofetón es el resultado de la frustrada «tensión por satisfacer el deseo amoroso» ${ }^{37}$. Observemos con Torres a propósito de este episodio fundamental de la intriga:

brota la sangre en el escenario de una manera poco habitual; brota una sangre extraña provocada por la mano de una mujer; sangre de hombre sobre un lienzo provocada por una dama. [...] Mano que Diana le había pedido ya a Teodoro en su caída, caída física, caída amorosa y simbólica del primer acto. Ahora es Diana la

hermosa protagonista disfrazada de fregona. Por lo que se rompe la rígida geometría de múltiples bodas que suele cerrar las comedias domésticas».

30. Lope de Vega, El perro del hortelano, pp. 134-135, vv. 2209-2222.

31. Rouane Soupault, 2010, p. 917; la autora aísla en el repertorio lopesco algunos recursos dramáticos que evidencian la necesidad de la dama de confesar su deseo, pasando por alto el caso emblemático de la bofetada. 
que le da la suya y en ese acto impone, exige, rompe y vierte el símbolo mismo de su deseo y de su diferencia, la sangre ${ }^{32}$.

La Condesa intenta justificar su gesto violento, indigno de su linaje, restándole importancia y diciendo al conde Federico que se trata tan solo de «enojos que pasan / entre criados y dueños» ${ }^{33}$. Teodoro, por su parte, hablando con Tristán no tiene ningún inconveniente en explicar las razones de los desatinos de su dueña: «está loca / de un amoroso deseo» ${ }^{34}$. La relevancia simbólica del bofetón en la construcción dramática de la pieza no se le escapa al gracioso, quien, comentando la solícita visita que Diana hace al trastornado secretario, llevándose su pañuelo ensangrentado, dice a su amo con sorna: «Pagó la sangre y te ha hecho / doncella por las narices» 35 .

El violento acto de la Condesa cabe leerlo también en una clave mítico-simbólica que trasciende la intriga cómica de esta pieza cumbre del teatro lopesco, a la luz de la peculiar caracterización de este personaje, quien lleva el nombre de la diosa de la caza, violenta, castigadora, y vinculada al frío y maléfico mundo lunar. Según hace notar sutilmente aún Torres: «La casta Diana penetra en el misterio amoroso ajeno y lo destruye» ${ }^{36}$.

Ahora bien, mucha razón tienen Fernández y Martínez-Carazo al subrayar que la bofetada es «la transgresión más patente en lo que atañe a los códigos sociales de conducta» de Diana en tanto que miembro de la aristocracia, así como al advertir que en la transposición cinematográfica la posterior reacción de remordimiento de la condesa de Belflor

es la excusa perfecta para que nuestra directora filme una nueva transgresión obligando a Diana a bajar presurosa hasta la cocina de palacio, lugar indigno de una dama, para interesarse por Teodoro. [...] Lope omite toda localización específica de esta escena limitándose a acotar: «Sale la Condesa» [...] Si la Diana de Lope únicamente pierde los estribos en la escena de la bofetada, la Diana de Miró, los pierde doblemente y duplica su capacidad transgresora ${ }^{37}$.

Con todo, la transgresión de Diana es relativa, puesto que Teodoro, a nivel estamental, no es más que un criado. En cambio, la dama de comedia que sobrepasa

32. Torres, 1996, p. 403; cfr. Carreño, 1992, p. 89: «Vehementes son los celos de Diana al notar en Teodoro una segunda inclinación hacia Marcela. Desgarra su rostro con un terrible bofetón que compensa, y a cambio del pañuelo ensangrentado, con dos mil escudos. [...] Se confirma la imagen del perro referida a la condesa quien "después que muerde halaga" (v. 2356), pasando del gozar al sádico hacer doler (una forma de placer) con inusitada frecuencia»; González, 2003, p. 99: «la violencia y el amor se aúnan en una dimensión de extraña sensualidad intensificada cuando Diana se lleva el lienzo manchado de sangre, mudo testimonio de su pasión y del contacto violento con Teodoro, después de compensarlo generosamente».

33. Lope de Vega, El perro del hortelano, p. 135, vv. 2226-2227.

34. Lope de Vega, El perro del hortelano, p. 137, vv. 2268-2269

35. Lope de Vega, El perro del hortelano, p. 140, vv. 2353-2354.

36. Torres, 1996, p. 397.

37. Fernández y Martínez-Carazo, 2006, p. 325. 
realmente los límites del decoro golpeando a un noble aún por los celos amorosos es la Lisarda de Las manos blancas no ofenden de Calderón. El episodio del bofetón se inserta en el último acto, pero ya en el incipit de la pieza Patacón, expresando sus temores por las violentas reacciones de la mujer, porque tiene que comunicarle que su dueño, Federico Ursino, está a punto de marcharse, lo anticipa de forma burlesca:

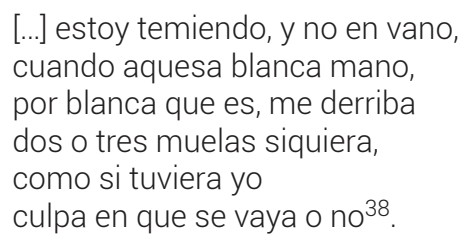

De hecho, el galán, al igual que los demás caballeros de la pieza, anda enamorado de la sin par Serafina, que había rescatado de un incendio, olvidándose de su primera enamorada. Por lo que Lisarda se echa en su seguimiento disfrazada de hombre. En el último acto ambos asisten a unos festejos organizados en la corte de Ursino en loor de Serafina, y cuando Carlos reacciona con desasosiego frente a la fineza de Carlos, quien devuelve un guante caído a la anfitriona, proclamando que nadie la merece más que él, Lisarda a su vez, arrebatada por la furia amorosa, «Le da una bofetada»39. Su violenta acción, muy a diferencia que en El perro del hortelano, crea una situación muy complicada para el personaje masculino. En efecto, la dama está embozada y en traje varonil, pero Federico, por la presencia de Enrique, padre de ella, y para no manchar su honra, no puede revelar su identidad. No obstante, si no lo hace corre el riesgo de que todo el mundo crea que él rehúsa vengarse de una afrenta, hecho indigno de un caballero. La propia Serafina lo incita diciendo: «¿Qué esperáis? Dadle la muerte». A estas alturas, a Federico no le queda más remedio que revelar de forma oblicua que su ofensor es una mujer, sin explicitar quién es, recurriendo a la frase proverbial que constituye el rótulo de la pieza:

Toma la mano a Lisarda, y la enseña a todos

Sabed que... tiene esta mano, y siendo, como es, tan blanca, agravio no ha sido, pues las manos blancas, no agravian 40 .

Sin embargo, no logra apaciguar a los demás, especialmente a Serafina, quien expresa sus propios celos, confesando a Nise:

38. Calderón, Las manos blancas no ofenden, p. 1078.

39. Calderón, Las manos blancas no ofenden, p. 1114.

40. Calderón, Las manos blancas no ofenden, p. 1114; ver al respecto Fernández Mosquera, 2015, pp. 327328: «La mujer [...] no ofende porque quiere sino porque no puede. Esa incapacidad de ofender es, en sí misma, una infravaloración de la condición femenina de la que el refrán no es más que un reflejo paremiológico. Y sobre esa minusvaloración del papel femenino Calderón construye la acción y los personajes». 

[...] aunque mano tan blanca
no puede agraviar su honor, agraviándome a mí el alma, miente quien dijere que las manos blancas no agravian ${ }^{41}$.

El gracioso contribuye a poner en tela de juicio la solución pacífica de su dueño, echando mano de la misoginia propia de la dimensión burlesca de su estatuto dramático:

señor, ¿qué remedio tienes

sino entregar a Lisarda?

$[\ldots]$

será un mal ejemplo éste;

Sí, porque

que si las mujeres ven

que andándose las mujeres

cachetes dando a los hombres,

hay bobos que las defienden,

maldita de Dios la que

la doctrina no aproveche,

y andarán toda la vida

matándonos a cachetes ${ }^{42}$.

Más tarde, casi en el cierre, Patacón se halla en una situación paralela a la del principio de la obra, teniendo que justificar la ausencia de su dueño esta vez a Serafina, y lo hace con una jocosa referencia al episodio de la bofetada:

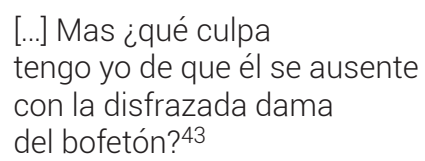

Finalmente, en el remate de los versos, tras el anuncio del tergiversado matrimonio entre los dos protagonistas, el criado del galán se encarga de matizar el sentido de la frase paremiológica aludiendo con malicia al violento temperamento de la primera dama44: «Con que corriente / queda refrán, que las blancas / manos no agravian, mas duelen» ${ }^{45}$.

Al margen, me parece interesante apuntar que tanto El perro del hortelano como Las manos blancas no ofenden son comedias palatinas ambientadas en una Italia fantástica, las cuales, dicho sea de paso, presentan unas analogías llamativas que

41. Calderón, Las manos blancas no ofenden, p. 1115.

42. Calderón, Las manos blancas no ofenden, p. 1116.

43. Calderón, Las manos blancas no ofenden, p. 1122.

44. Ver Fernández Mosquera, 2015, p. 303: «La clave de la comedia está en esta actitud resolutiva y vengadora de Lisarda que es, en sí misma, también una caracterización masculinizante».

45. Calderón, Las manos blancas no ofenden, p. 1124. 
parecen remitir a un sutil diálogo intertextual que nos proponemos analizar en otro lugar ${ }^{46}$. En todo caso, al respecto sería oportuno preguntarse si sus respectivos autores han escogido dicho ámbito geográfico pensando en la gestualidad y en la caracterización de los comici dell'Arte; recuerdo de paso que la típica innamorata de los scenari suele ser pasional y, si olvidada, se muestra violenta y vengativa ${ }^{47}$.

En contextos teatrales carnavalescos la víctima de un bofetón dado por una mujer puede ser tanto un hombre como otra mujer. En el baile dramático ¡Ay, ay, ay! y el sotillo, posiblemente de Lope ${ }^{48}$, dos lacayos requiebran a sendas fregonas al ritmo de la música; de repente una de ellas se enfada por las críticas de Beltrán:

\begin{tabular}{|c|c|}
\hline BELTRÁN & ¡Oh, qué mal que lo han bailado \\
\hline \multirow[t]{2}{*}{ FREGONA 1} & ¡Miente el lacayo! \\
\hline & Dale un bofetón ella \\
\hline BELTRÁN & ¡Ay, ay! \\
\hline FREGONA 1 & $\begin{array}{l}\text { Estopilla del cambray } \\
\text { diga quien se lo ha enseñado. }\end{array}$ \\
\hline BELTRÁN & $\begin{array}{l}\text { ¡Es barro una bofetada } \\
\text { para no aprender un son! } 49\end{array}$ \\
\hline
\end{tabular}

En el acto intermedio de Los locos de Valencia, pieza urbana del joven Lope, Laida, criada de Fedra, que es la hija del administrador del hospital, al igual que su ama se enamora en balde de Floriano, el protagonista que simula haber perdido el seso para escapar de la justicia. En un momento dado, casi en el cierre del acto intermedio, su frustración amorosa la lleva a fingirse loca, obligando a su ama a una grotesca inversión de papeles, conforme a la carnavalización dominante en la obra ${ }^{50}$. Así, pues, las dos mujeres protagonizan una festiva secuencia dramática que se interrumpe en el momento en que la dueña ya no aguanta la ficción:

46. De momento, me limito a señalar el carácter violento y celoso de la dama protagonista, el bofetón que ella propina a su enamorado, la mención de Belflor (en el texto recogido en TESO), y el nombre de un personaje secundario que coincide con el del galán protagonista lopesco, es decir, Teodoro.

47. Ver Nicoll, 1965, p. 166: «Le passioni d'amore, specialmente da parte delle fanciulle, erano incontrollabili e violente. Abbiamo già visto come un'Isabella, credendosi dimenticata, possa diventare pazza furiosa; e se non impazzisce, cinquanta volte su cento mette mano a stiletti e fiale di veleno».

48. Ver Sáez Raposo, 2012, p. 380: «de todos los bailes analizados, es el único que recurre, entre otras, a las mismas formas métricas (el romance y la seguidilla) que el denominado Baile de Apolo y Dafne. Es por todo ello el candidato que reúne los mejores requisitos para ser adjudicado al genio creador de Lope». 49. Cotarelo y Mori, 1911, p. 477b, n. 189.

50. Ver García Lorenzo, 1989, p. 219: «Mundo al revés, en fin, la actitud que, a causa de su "locura de amor", tomarán también Laida y Fedra, la primera convirtiéndose en reina y la segunda haciéndose también la loca y recibiendo órdenes e incluso una bofetada de la que (volvamos a la cordura) es su criada»; Tropé, en Lope, Los locos de Valencia, p. 48: «En Los locos de Valencia el ejercicio liberador que implica el Carnaval se manifiesta en la actuación y en el discurso de los locos fingidos de esta comedia y en múltiples aspectos vinculados con el argumento mismo de la obra»; pp. 50-51: «Anómala y representa- 


$\begin{array}{ll}\text { FEDRA } & \text { ¿Reina vos? ¡Mentís, villana! } \\ \text { LAIDA } & \text { ¿Mentís? ¡Tomá un bofetón! } \\ \text { FEDRA } & \text { ¿Bofetón a mí? ¡Ah, traición! } \\ & \text { ¡Esperad, doña avellana! }{ }^{51}\end{array}$

Tras lo cual, la acotación informa «Ásganse las dos», típica situación de comicidad situacional y dinámica propia de una comedia burlesca o de un retablo de títeres ${ }^{52}$.

Una variante original de la situación risible de dos mujeres golpeándose se incrusta en la jornada II de El laberinto de amor de Cervantes: Julia y Porcia, dos primas que se han escapado del encierro doméstico para ir en búsqueda de sus respectivos amados, Anastasio y Manfredo, en una secuencia dramática se portan como los típicos criados que parodian la situación protagonizada por sus respectivos amos, pese a que, como es bien sabido, la experimentación teatral cervantina, por lo general, no se ajusta a la fórmula lopesca. Asistiendo a una riña que se produce entre los dos jóvenes, las mozuelas empiezan también a pelearse hasta que la mano de Porcia/Rutilio, que Rico García define «un ejemplo acabado de dama donaire» ${ }^{53}$, propina el golpe inesperado y totalmente gratuito. Así reacciona su asombrada prima:

JULIA Rutilio, di, ¿no es este desvarío?

¿Bofetada en mi rostro? ¡Ya el coraje

ha llegado a su punto y no es posible

que temor o respeto aquí le ataje ${ }^{54}$ !

Los demás personajes asisten a la disparatada pelea sin entender los motivos que la han ocasionado, y es Manfredo quien, dirigiéndose al fingido pastorcillo, destaca su pertenencia al mundo al revés de la locura: «El seso, al parecer, tienes perdido» ${ }^{55}$. También en este caso la teatralidad de los comici dell'Arte podría haber influido, tal vez, en la conformación de esta secuencia dramática.

Bien mirado, las bofetadas del baile dramático atribuido a Lope, de Los locos de Valencia, y del Laberinto de amor no hacen sino aprovechar con finalidades mera-

tiva de la vuelta al revés del mundo es también la inversión de los papeles respectivos de la noble Fedra y de Laida, su criada, cuando los juegos paródicos del fingimiento de la locura conducen a esta última a tratar a su ama como una sirvienta y cuando aquélla le sigue el juego y finge acatar sus grotescas órdenes. La farsa carnavalesca alcanza su punto cumbre con el bofetón que la criada propina a Fedra». 51. Lope de Vega, Los locos de Valencia, pp. 262-263, vv. 1993-1996.

52. Por ejemplo, en Cada cual con su cada cual, comedia burlesca anónima, en una secuencia de la jornada de apertura las dos infantas se agarran por el moño para manifestar sus celos recíprocos (vv. 348 acot. y ss.); Mata Induráin, 2005, p. 1197, destaca la rivalidad grotesca de las dos hermanas en Castigar por defender y de las infantas en Céfalo y Pocris, piezas que también pertenecen a dicho subgénero del teatro cómico.

53. Rico García, en Cervantes, Comedias y tragedias, volumen complementario, p. 131.

54. Cervantes, El laberinto de amor, p. 626, vv. 1409-1412.

55. Cervantes, El laberinto de amor, p. 628, v. 1447. 
mente lúdicas un gesto teatral que en los demás casos analizados asume, por lo visto, una gama variada de significados e implicaciones en relación con el subgénero dramático y con el sexo y el papel de los que propinan o reciben el bofetón. En definitiva, y con muy pocas excepciones, los ejemplos espigados no hacen sino confirmar que un lance violento, aunque sea el de un mero bofetón, pertenece al mundo masculino, y que puede atañer al comportamiento femenino tan solo en el mundo al revés de la risa carnavalesca, siendo los celos amorosos o el gratuito disparate festivo los pretextos dramáticos para que las manos blancas puedan soltar una bofetada más bien dada.

\section{Bibliografía}

Anónimo, Cada cual con su cada cual, ed. Marcella Trambaioli, Pamplona, Servicio de Publicaciones de la Universidad de Navarra (Colección BIADIG, Biblioteca Áurea Digital, 25), 2014.

Calderón de la Barca, Pedro, Las manos blancas no ofenden, en Obras completas, II, Comedias, ed. Ángel Valbuena Briones, Madrid, Aguilar, 1956, pp. 1075-1124.

Campana, Patrizia, «In medias res: diálogo e intriga en el primer Lope», Criticón, 81 82, 2001, pp. 71-87.

Carreño, Antonio, «La semántica del engaño: El perro del hortelano de Lope de Vega», en Busquemos otros montes y otros ríos. Estudios de la literatura española del Siglo de Oro dedicados a Elias L. Rivers, ed. Brian Dutton y Victoriano Roncero López, Madrid, Castalia, 1992, pp. 75-97.

Castro Rivas, Jéssica, «Violencia y enredo en la comedia cómica calderoniana», en La violencia en el teatro de Calderón, Archivum Calderonianum, 13, ed. Manfred Tietz y Gero Arnscheidt, Vigo, Editorial Academia del Hispanismo, 2014, pp. 93-105.

Cervantes, Miguel de, El laberinto de amor, ed. José Manuel Rico García, en Comedias y tragedias, Madrid, Real Academia Española, 2015, pp. 575-685.

Cotarelo y Mori, Emilio, Colección de entremeses, loas, bailes, jácaras y mojigangas desde fines del siglo XVI a mediados del siglo XVIII, Madrid, Éd. Bailly-Bailliére, 1911.

Fernández, Esther, y Martínez-Carazo, Cristina, «Mirar y desear: la construcción del personaje femenino en El perro del hortelano de Lope de Vega y de Pilar Miró», Bulletin of Spanish Studies, LXXXIII, 3, 2006, pp. 315-328.

Fernández Mosquera, Santiago, «El doble disfraz en Las manos blancas no ofenden: la discreta modernidad de Calderón. Estrategias de representación», en Calderón: texto, reescritura, significado y representación, Madrid/Frankfurt am Main, Iberoamericana/Vervuert, 2015, pp. 297-332. 
García Lorenzo, Luciano, «Amor y locura fingida: Los locos de Valencia, de Lope de Vega», en El mundo del teatro español en su Siglo de Oro. Ensayos dedicados a John E. Varey, ed. José María Ruano de la Haza, Ottawa, Dovehouse Editions Canada, 1989, pp. 213-228.

González, Aurelio, «La palabra y el gesto de amor en Lope», en Amor y erotismo en el teatro de Lope de Vega. Actas de las XXV Jornadas de Teatro Clásico de Almagro (Almagro, 9- 17 de julio de 2002), ed. Felipe B. Pedraza Jiménez, Rafael González Cañal y Elena Marcello, Almagro, Festival de Almagro/Universidad de Castilla-La Mancha, 2003, pp. 85-107.

Mata Induráin, Carlos, «La parodia del retrato femenino en la comedia burlesca del Siglo de Oro», en Actas del Congreso «El Siglo de Oro en el nuevo milenio», ed. Carlos Mata y Miguel Zugasti, Pamplona, Eunsa, 2005, vol. II, pp. 1195-1212.

Nicoll, Allardyce, II mondo di Arlecchino. Studio critico della Commedia dell'Arte, Milano, Bompiani, 1965.

Rouane Soupault, Isabelle, «De cómo confesar el deseo o cuando las damas desdicen de su nombre», en Cuatrocientos años del «Arte nuevo de hacer comedias» de Lope de Vega, ed. Germán Vega García-Luengos y Héctor Urzáiz Tortajada, Valladolid/Olmedo, Secretariado de Publicaciones e Intercambio Editorial de la Universidad de Valladolid/Ayuntamiento de Olmedo, 2010, pp. 917-927.

Sáez Raposo, Francisco, «"Que también sé yo hacer bailes": Lope de Vega y el baile dramático», Revista de Filología Española, XCII, 2, 2012, pp. 363-384.

Tirso de Molina, Doña Beatriz de Silva, ed. Manuel Tudela, en Obras completas, Cuarta parte de comedias, I, Madrid/Pamplona, Revista Estudios/GRISO-Universidad de Navarra, 1999, pp. 833-989.

Tirso de Molina, El amor médico, ed. Blanca Oteiza, en Obras completas, Cuarta parte de comedias, I, Madrid/Pamplona, Revista Estudios/GRISO-Universidad de Navarra, 1999, pp. 651-832.

Tirso de Molina, El condenado por desconfiado, ed. Ciriaco Morón y Rolena Adorno, Madrid, Cátedra, 1987.

Tirso de Molina, La celosa de sí misma, en Obras dramáticas completas, III, ed. Blanca de los Ríos, Madrid, Aguilar, 1952, pp. 1433-1492.

Torres, Milagros, «Paradojas de Diana», en Studia Aurea. Actas del III Congreso de la AISO (Toulouse, 1993), II, Teatro, ed. Ignacio Arellano, María del Carmen Pinillos, Frédéric Serralta y Marc Vitse, Pamplona/Toulouse, GRISO/LEMSO, 1996, pp. 395-404.

Trambaioli, Marcella, La épica de amor en las comedias de ambientación urbana de Lope de Vega, y su contexto representacional cortesano, Madrid, Visor Libros, 2015. 
Trambaioli, Marcella, «Matadoras de hombres en la escritura de Lope de Vega: de las octavas de los poemas cultos a las tablas», en prensa.

Vega, Lope de, Del mal, lo menos, ed. Gabriel Padilla, en Comedias de Lope de Vega. Parte IX, Barcelona/Lleida, Prolope-Universitat Autònoma de Barcelona/Milenio, 2007, vol. II, pp. 817-923.

Vega, Lope de, El duque de Viseo, ed. Manuel Calderón, en Comedias de Lope de Vega. Parte VI, Barcelona/Lleida, Prolope-Universitat Autònoma de Barcelona/Milenio, 2005, vol. II, pp. 1031-1160.

Vega, Lope de, El primero Benavides, ed. Silvia Iriso Ariz, en Comedias de Lope de Vega. Parte II, Barcelona/Lleida, Prolope-Universitat Autònoma de Barcelona/ Milenio, 1998, vol. II, pp. 839-1022.

Vega, Lope de, La fuerza lastimosa, ed. Montgrony Alberola, en Comedias de Lope de Vega. Parte II, Barcelona/Lleida, Prolope-Universitat Autònoma de Barcelona/Milenio, 1998, vol. I, pp. 69-243.

Vega, Lope de, La moza de cántaro, en Obras selectas, ed. Federico Carlos Sainz de Robles, Madrid, Aguilar, vol. I, pp. 999-1028.

Vega, Lope de, Las ferias de Madrid, ed. David Roas, en Comedias de Lope de Vega. Parte II, Barcelona/Lleida, Prolope-Universitat Autònoma de Barcelona/Milenio, 1998, vol. III, pp. 1823-1954.

Vega, Lope de, Los locos de Valencia, ed. Hélène Tropé, Madrid, Editorial Castalia, 2003.

Vega, Lope de, Por la puente, Juana, en Obras escogidas, I, ed. Federico Carlos Sainz de Robles, Madrid, Aguilar, 1991, pp. 1279-1306. 